\title{
Research for Multi-source Data Management System of Digital Mine
}

\author{
Shiyao Xiang* \\ College of Geoscience and Surveying Engineering, China University of Mining and Technology(Beijing), \\ Beijing 100083, China \\ xiangshiyao1989@163.com
}

Keywords: Digital mine, Open-pit coal mine, Multi-source data, GIS

\begin{abstract}
According to guiding ideology of digital mine construction as well as the production and operating conditions of open-pit coal mine in China, this paper designs the multi-source data management system of digital mine for open-pit coal mine. 6 kinds of spatial data and 3 kinds of non-spatial data were managed through the system to achieve the purposes of data fusion and data mining. The data characteristics and storage structure were roundly introduced in this paper. GIS component development was used to design the system. The practical application shows that the system could improve the management efficiency of data in open-pit coal mine and visually and concretely present the mining area. In this way, the convenience and support for management and production of mining area could be brought.
\end{abstract}

\section{Introduction}

As the concept of digital mine has been proposed, the informatization and intellectualization have become the important symbol for mine modernization. The purposes of implementing digital mine is to promote resources visualization and management digitization and roundly accelerate production process visualization, production control automation and enterprise management informatization [1]. Mine production is a complex system and different kinds of data will be generated during the process of mine production and operation. Data is the basis for correct decision, and efficient and reasonable data management is a priority during the digital mine construction. At present, many scholars have studied the data management of digital mine, for example, Xiong classified and coded spatial features of underground mine [2]. Li et al. studied the fusion method of multi-source heterogeneous data in digital mine [3]. Kher et al. proposed to manage the accident data and production data of underground coal mine in a unified way [4]. According to this problem, this paper puts forward to apply GIS into data management in mine. The multi-source data management system of digital mine has been designed through GIS component development to achieve the purpose of managing the data efficiently and conveniently. In this way, data mining and auxiliary decision-making can be realized at the same time. Because there are so many types of mines and different mining methods, this paper chooses the open-pit coal mine as the research object. The corresponding multi-source data management system has been designed depending on the study for data characteristics and types of open-pit coal mine.

\section{System Structure}

Based on the practical work of geology, surveying, mining and other departments in open-pit coal mine, the corresponding software has been designed to integrate the various data and improve production efficiency and decision-making level. In this paper, SuperMap Objects 6 components 
package has been used to design the multi-source data management system of digital mine to achieve data integrated management, classified storage and convenient update relying on Visual Studio 2008.

According to the production and operation characteristics of open-pit coal mine, the data selected in this paper can be divided into two types: spatial data and non-spatial data. Spatial data have spatial attribute and can be located through the geographic coordinates. The non-spatial data do not have this attribute.

The database structure of the system is shown in Fig. 1.

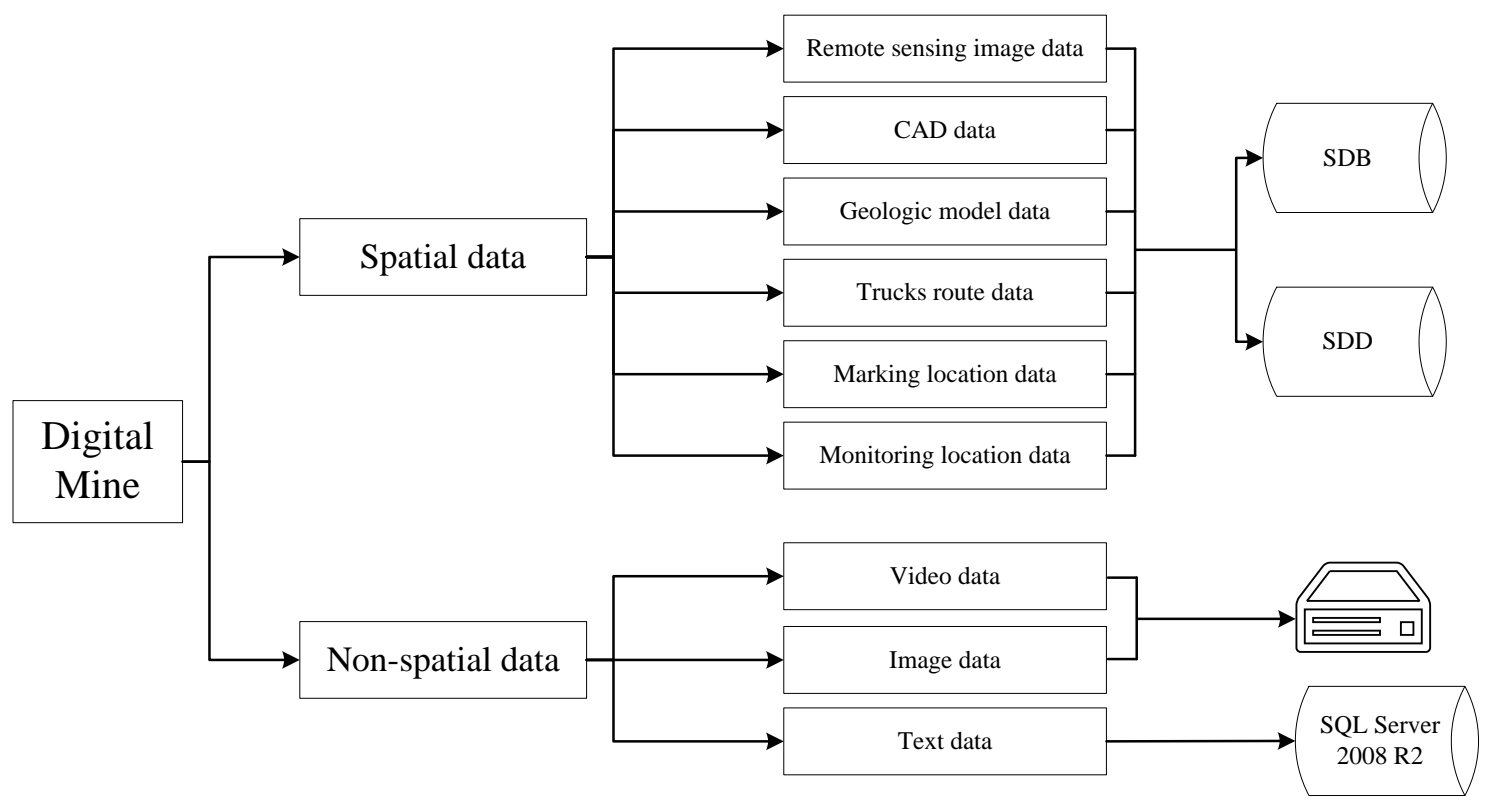

Fig. 1 Database structure

The spatial data in this paper include 6 types: remote sensing image data, CAD data, geological model data, trucks route data, marking location data and monitoring location data. Non-spatial data include 3 types: video data, image data and text data. The space entity and its corresponding attributes of each type of spatial data are stored in SDB and SDD databases of SuperMap. The video data and image data of non-spatial data are stored in the local hard disk, and the text data of non-spatial data is stored in SQL Server 2008 R2 database.

Because the spatial data have spatial attribute, storing them in a unified database can avoid creating multiple databases and wasting the storage resources. In addition, data fusion and data mining can be realized and information island can also be avoided. Due to the video data and image data account for bigger storage space and the file formats are simple, storing them in local hard disk can simplify the process of data storing and reading to reduce processing time. Because the text data amounts for small storage space, storing it in SQL Server 2008 R2 database can realize the data encryption and facilitate data revising and reading at the same time.

These data have different features. Remote sensing image data is obtained by aerial drones photographing the mining area, and it is the real and intuitive record of environment and running status of the mining area [5]. CAD data is the basic data for surveying and mapping as well as earthwork calculating of the mining areas [6]. Geological model data is the 3D model of mineral deposit, and it is an important means to calculate ore grade and reserve, and design mining ways [7]. Trucks route data is the routes of trucks, including starting position, direction, distance and so on. Marking location data including the marking locations in the map is used to deal with accidents or assign tasks. Monitoring location data includes the locations of the video monitors in the mine stope, refuse dump, road and other regions. The video monitoring is one of the important means to ensure 
mine safe operation [8].The non-spatial data in the system including video data, image data and text data are the introduction of mining area, which are used to realize the purpose of presenting the mining area.

Finally, data management, map operations, data analysis and mining area display can be realized through the system. Every function can be subdivided into specific functions, for example, data management includes data classification, data storage, etc.; map operations includes map view, layers control, etc.; data analysis includes reserve analysis, grade analysis, etc.; mining area display includes environmental display, cultural display, etc., as shown in Fig. 2.

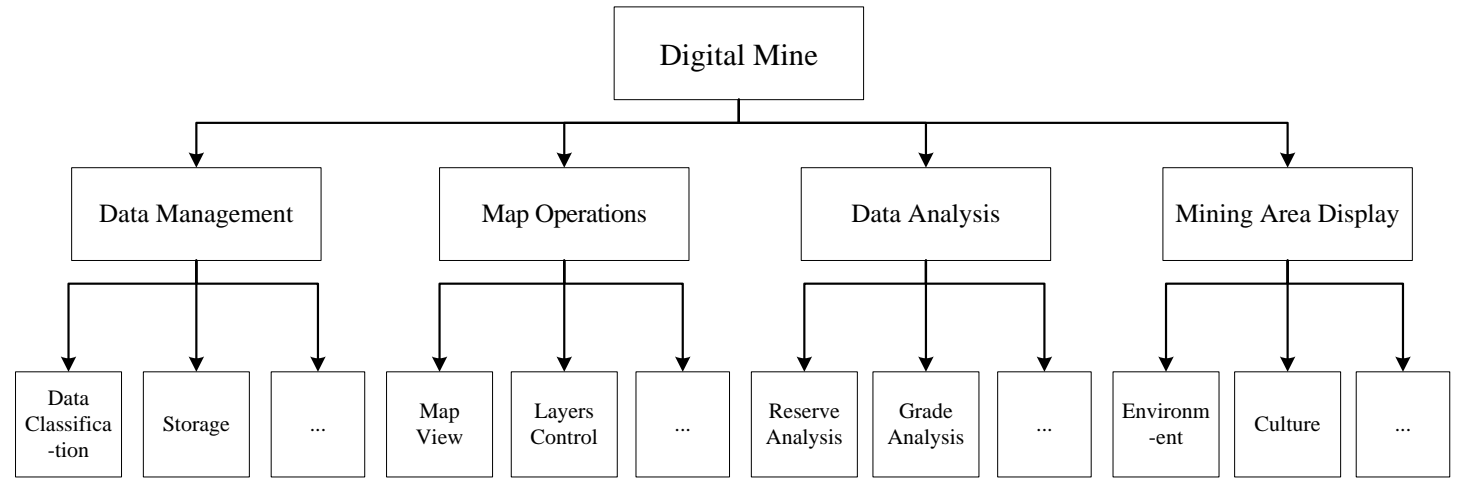

Fig. 2 System functions

\section{Application Example}

A large open-pit coal mine in China is regarded as the research object to design and establish the system. The mining area is large and mining time is long. The modernization and informatization level of production and management is high.

Through investigation and research of the mining area, multi-source data management system of digital mine has been designed to realize the integration management of spatial data and display of non-spatial data. In the realization of data management, the basic conditions of mining area can be described roundly. System interface is shown in Fig. 3.

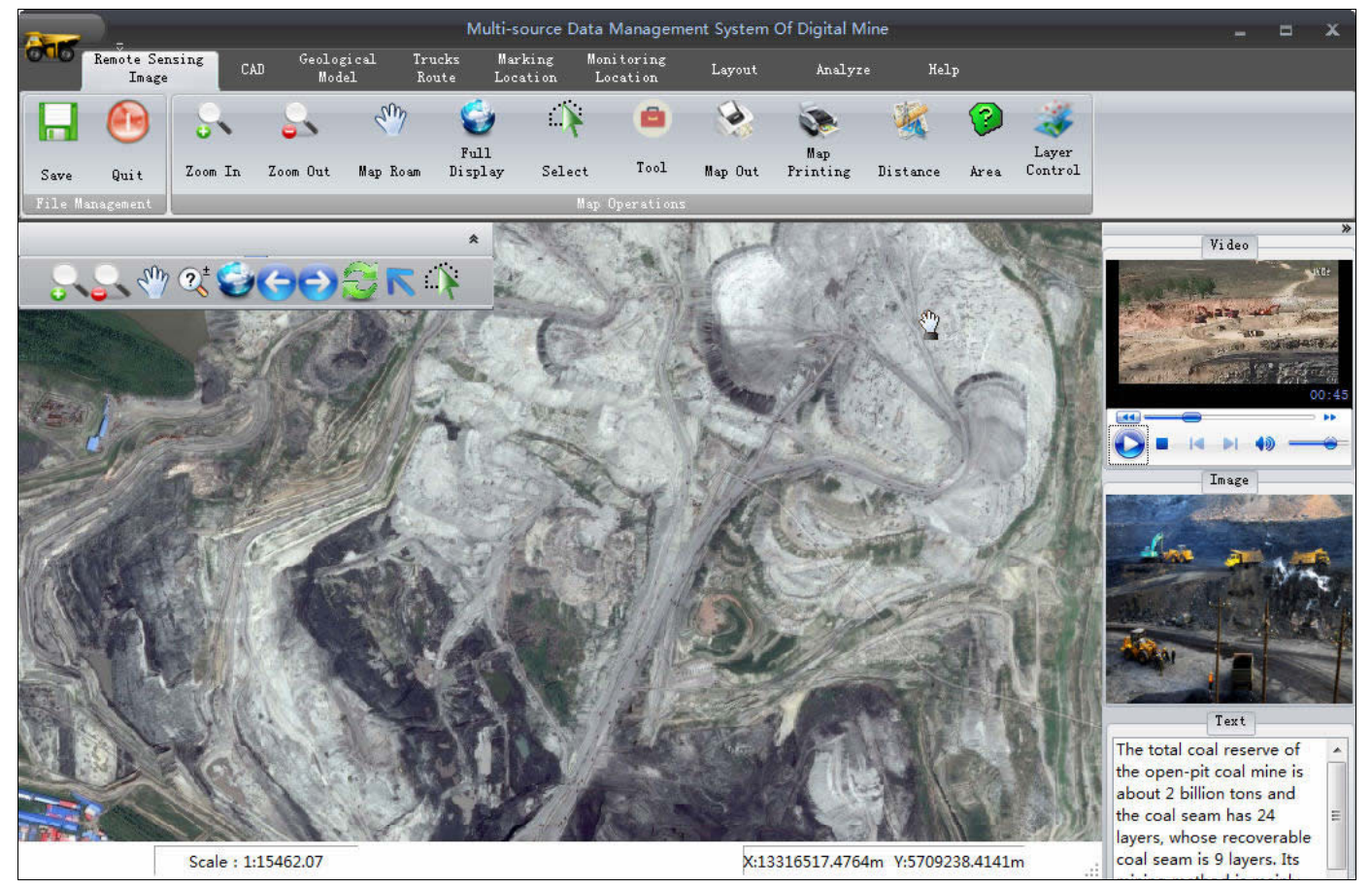

Fig. 3 System interface 
As shown in Fig. 3, the remote sensing image data is shown in the middle of the system interface. The remote sensing image data, CAD data, geological model data, trucks route data, marking location data and monitoring location data can be switched in turn through the toolbar at the top of the system. At the same time, the map operations, measurement, analysis and other functions of spatial data can be implemented to achieve effective utilization of spatial data. The "Layout" function of system can realize the output of map. The "Analyze" function of system can achieve grade analysis, statistical analysis, and so on. On the right side of the system interface, video data, image data and text data of the mining area are shown in turn. These data are the real record of the mining area and can display mining area roundly to give a comprehensive understanding of the mining area.

\section{Conclusion}

Combining with the production and operation characteristics of open-pit coal mine, GIS components development has been applied into the construction of digital mine. The integrated management of spatial data has provided convenience for data storage and application. In this way, the multi-angle, multi-dimensional and multi-level access can be achieved to obtain the spatial information of mining entities to provide help and support for data fusion and data mining. The integrated application of multi-source spatial data can bring more rationality to data analysis and data applications to give a more accurate decision support. Through the application of video data, image data and text data, users can get a clearer understanding of the mining area. The actual application shows that the system could improve the management level of the mining data. In addition, the data in mining area should be collected in a comprehensive way and the types of data in the system should be increased in the future research.

\section{References}

[1]L.X. Wu, Z.R. Yin, Y.P. Zhong, Restudy on digital mine: characteristics, framework and key technologies, J. China Coal Soc. 28 (2003) 1-7.

[2]S.M. Xiong, Classification and coding design for spatial features of underground mine, Ind. Mine Autom. 41 (2015) 23-27.

[3]G.Q. Li, N.L. Hu, Y.M. Chen, Study on technologies of multi-source heterogeneous data fusion for digital mines, China Min. Mag. 20 (2011) 89-93.

[4]A.A. Kher, R.R. Yerpude, Modeling accident data for decision support in underground coal mines, Int. J. Eng. Res. Technol. 3 (2014) 654-657.

[5]Z.H. Xu, L.X. Wu, S.J. Chen, Z. Wang, Method of engineering volume monitoring and calculation for open-pit mine from UAV images, J. Northea. Univ. (Nat. Sci.). 37 (2016) 84-88.

[6]D.D. Pang, H.F. Ma, D.W. Pang, Methods of drawing mine three-dimensional map and comparative analysis, Coal Technol. 33 (2014) 272-274.

[7]Z.Q. Luo, B. Zhang, X.M. Liu, H. Lu, C. Li, 3D visualization method of analysis and estimation of orebody grade and reserves, Nonf. Met. (Min. Sect.). 60 (2008) 23-27.

[8]X.H. Zhang, S. Zhang, S. Fang, Y. Cao, Clearing research on fog and dust images in coalmine intelligent video surveillance, J. China Coal Soc. 39 (2014) 198-204. 